\title{
Mitochondrial DNA Damage as a Mechanism of Cell Loss in Alzheimer's Disease
}

\author{
Suzanne M. de la Monte, Tri Luong, Thomas R. Neely, Diedra Robinson, and \\ Jack R. Wands
}

Departments of Medicine and Pathology, Rhode Island Hospital, Brown University School of Medicine, Providence, Rhode Island

SUMMARY: Aging is associated with impaired mitochondrial function caused by accumulation of oxygen free radical-induced mitochondrial (Mt) DNA mutations. One prevailing theory is that age-associated diseases, including Alzheimer's disease (AD), may be precipitated, propagated, or caused by impaired mitochondrial function. To investigate the role of MtDNA relative to genomic (Gn) DNA damage in AD, temporal lobe samples from postmortem AD $(n=37)$ and control $(n=25)$ brains were analyzed for MtDNA and GnDNA fragmentation, mitochondrial protein and cytochrome oxidase expression, MitoTracker Green fluorescence (to assess mitochondrial mass/abundance), and 8-oxo-7,8-dihydro-2'-deoxyguanosine (8-OHdG) immunoreactivity. Brains with $A D$ had more extensive nicking and fragmentation of both MtDNA and GnDNA as demonstrated by agarose gel electrophoresis, end-labeling, and the in situ terminal deoxynucleotide transferase end-labeling (TUNEL) assay, and only the brains with AD had detectable 8-OHdG immunoreactivity in cortical neurons. Increased MtDNA damage in AD was associated with reduced MtDNA content, as demonstrated by semiquantitative PCR analysis and reduced levels of Mt protein and cytochrome oxidase expression by Western blot analysis or immunohistochemical staining with image analysis. The finding of reduced MitoTracker Green fluorescence in AD brains provided additional evidence that reduced Mt mass/abundance occurs with $A D$ neurodegeneration. The presence of increased MtDNA and GnDNA damage in AD suggest dual cell death cascades in AD. Impaired mitochondrial function caused by MtDNA damage may render brain cells in AD more susceptible to oxidative injury and thereby provide a mechanism by which systemic or environmental factors could influence the course of disease. (Lab Invest 2000, 80:1323-1335).

$R$ ecent evidence suggests that aging and a number of prevalent age-associated diseases, including cancer, heart disease, and neurodegeneration, may be precipitated, propagated, or caused by impaired mitochondrial function resulting from oxygen free-radical damage and accumulation of mitochondrial (Mt) DNA mutations (Ozawa, 1995, 1997; Richter, 1992, 1995; Schapira, 1994) However, because of the broad impact that such conclusions could have on the strategies used to develop compounds for treating or preventing disease, detailed systematic studies using both human and experimental models are needed to formally prove this theory.

The major intracellular source of oxygen free radicals is the mitochondrial respiratory chain because it continuously produces superoxide under normal physiological conditions. Metabolic disturbances in mitochondrial function result in electron escape from the electron transport chain and attendant formation of hydroxyl radicals and hydrogen peroxide from superoxide. Increased oxidative stress causes further

Received May 3, 2000.

This work was supported by Grants AA-02666, AA-02169, and AA11431 from the National Institutes of Health.

Address reprint requests to: Dr. S. M. de la Monte, Pierre Galletti Research Building, Rhode Island Hospital, 55 Claverick Street, Room 419, Providence, Rhode Island 02903. Fax: 401444 2939; E-mail: delamonte@hotmail.com free-radical damage to mitochondria and MtDNA. Unlike genomic (Gn) DNA, MtDNA is not protected by histones or DNA-binding proteins, and MtDNA repair mechanisms have not yet been identified in the central nervous system. MtDNA damage after exposure to high levels of reactive oxygen species and free radicals is mediated by intramitochondrial accumulation of 8-oxo-7,8-dihydro-2'-deoxyguanosine (8-OHdG) (Richter, 1992, 1995). Incorporation of 8-OHdG into MtDNA causes base mispairing, random point mutations, and deletions. Importantly, damaged mitochondria can replicate because enzymes required for mitochondrial replication are encoded by GnDNA. Increased abundance of defective MtDNA that encodes respiratory enzymes may lead to impaired electron transport and enhanced production of reactive oxygen species, further oxidative stress, and damage to mitochondria. The problem is compounded by increased peroxidation of lipids and oxidative modification of proteins by reactive oxygen species and hydrogen peroxide. The exponential age-related accumulations of intramitochondrial 8-OHdG and mutated MtDNA suggest that the deterioration of organ function attributed to aging may be caused by somatically acquired MtDNA damage and impaired cellular energy production.

Increased levels of reactive oxygen species and free radicals could lead to enhanced apoptosis. In that context, apoptosis would be mediated by opening of 
the mitochondrial permeability transition pores, cytochrome c release into the cytosol, and activation of caspases that mediate DNA fragmentation and cytoskeletal protein cleavage. Apoptosis is a demonstrated mechanism of cell loss in Alzheimer's (AD) and other neurodegenerative diseases (de la Monte et al, 1997, 1998; Erro and Tunon, 1997; Su et al, 1996, 1997). However, there is also evidence that apoptosis in the setting of neurodegeneration is caused by increased susceptibility to oxidative damage and freeradical injury (Sayre et al, 1997a, 1997b; Smith et al, 1996, 1997; Smith and Perry, 1995; Stadelmann et al, 1998; Yan et al, 1995). Impaired mitochondrial function and accumulation of MtDNA mutations could reduce cellular tolerance for free-radical injury and thereby have a critical role in mediating cell loss in $A D$ and other neurodegenerative diseases. In the present study, we used agarose gel electrophoresis, endlabeling assays, the in situ terminal deoxynucleotide transferase end-labeling (TUNEL) assay, and Hoechst H33258 staining to analyze AD and control temporal lobe samples for evidence of MtDNA and GnDNA damage. In addition, we assessed MtDNA abundance, mitochondrial protein and cytochrome oxidase expression, and mitochondrial mass/abundance using a semiquantitative polymerase chain reaction (PCR) assay, Western blot analysis, immunohistochemical staining, and fluorescence labeling, respectively.

\section{Results}

\section{In Situ Detection of Apoptosis and DNA Fragmentation}

Apoptosis and DNA fragmentation were detected in tissue sections by TUNEL assay for nicked DNA and Hoechst H33258 staining. The TUNEL assay was used to label the $3^{\prime}$ ends of nicked or fragmented DNA using [14-biotin]dCTP and terminal deoxynucleotide transferase enzyme. The labeled DNA was detected with horseradish peroxidase-conjugated streptavidin and diaminobenzidine. Although apoptosis with TUNEL-positive nuclear DNA fragmentation has been described in $A D$ and other neurodegenerative diseases (de la Monte et al, 1997, 1998), we now provide evidence that the DNA fragmentation associated with $A D$ neurodegeneration is not confined to the nucleus. As shown in Figure 1, control brains exhibited virtually negative labeling by the TUNEL assay (Fig. 1A), whereas in $A D$, TUNEL $^{+}$nuclear (Fig. 1, B and E-F) and cytoplasmic/perinuclear (Fig. 1, C-D and F) labeling were readily detected in neurons and glial cells. In some $A D$ cases, the cytoplasmic $\mathrm{TUNEL}^{+}$labeling was more abundant than nuclear labeling, particularly in white matter glial cells (Fig. 1F), consistent with a previous report of increased proapoptosis gene expression involving both neurons and glial cells in $A D$ (de la Monte et al, 1997).

Hoechst H33258 binds to DNA and after a brief period of labeling (2 minutes), reveals nuclear condensation and fragmentation associated with apoptosis. In our experience, H33258 staining is a more sensitive and reproducible method for in situ detection of DNA damage in postmortem tissue. Deparaffinized, rehydrated sections of temporal lobe were stained with H33258 and examined with a fluorescence microscopy. H33258 staining of control brains showed lowlevel diffuse homogeneous labeling of nuclei (Fig. 1G). In contrast, all AD cases exhibited conspicuous H33258 labeling of condensed fragmented nuclei and apoptotic bodies in scattered cells (Fig. 1 hour), and corresponding with the TUNEL assay results, numerous cells (neurons and glial) in AD brains exhibited cytoplasmic (perinuclear) labeling, with or without associated nuclear labeling (Fig. 1I). To determine whether the cytoplasmic labeling by the TUNEL assay and H33258 staining represented mitochondrial DNA fragmentation, genomic (Gn) and mitochondrial (Mt) DNA were isolated from the same samples of temporal lobe tissue and analyzed by agarose gel electrophoresis and end-labeling.

\section{Increased Genomic DNA Fragmentation in $A D$}

GnDNA was isolated from fresh snap-frozen tissue harvested within 18 hours of death. GnDNA (10 $\mu \mathrm{g} /$ sample) was electrophoresed in a 3\% agarose gel that was subsequently stained with ethidium bromide and photographed under UV illumination. To quantify nicking or fragmentation of GnDNA, we also employed a highly sensitive primer-independent end-labeling assay based upon incorporation of $\left[\alpha^{32} \mathrm{P}\right] \mathrm{dCTP}$ at the $3^{\prime}$ hydroxyl ends of nicked DNA in the presence of Klenow large fragment DNA polymerase (Moyse and Michel, 1997). The labeled DNA was separated from free nucleotides and $\left[\alpha^{32} \mathrm{P}\right] \mathrm{dCTP}$ incorporation was measured using a scintillation counter. To ensure equivalent labeling and permit inter-group comparisons, the reactions were carried out simultaneously using a premix containing radiolabeled nucleotides and enzyme. In addition, the amount of DNA used in each reaction was verified by measuring the OD $260 / 280$ in replicate samples.

By agarose gel electrophoresis, control brains ( $n=$ 10) manifested predominantly high molecular weight DNA, although nearly all samples (23 of 25) had faint laddering patterns consistent with low levels of apoptosis. Among the AD cases, 18 of 37 showed conspicuous DNA fragmentation ladders, while the remainder had faint laddering patterns similar to control brains (Fig. 2A). Using a more sensitive end-labeling assay, GnDNA fragmentation was detected in both AD and control samples (Fig. 2B). This result was expected because the tissues were obtained by autopsy. Nonetheless, the mean labeling indices (cpm/ 100 ng DNA) were 3-fold higher in AD relative to aged control brains $(p<0.001)$. Corresponding with the agarose gel electrophoresis results, the samples that showed obvious DNA laddering had the highest labeling indices, and those with latent DNA laddering had relatively low labeling indices (data not shown). Reanalysis of the samples yielded consistent results, ie, coefficients of variation less than $10 \%$. 


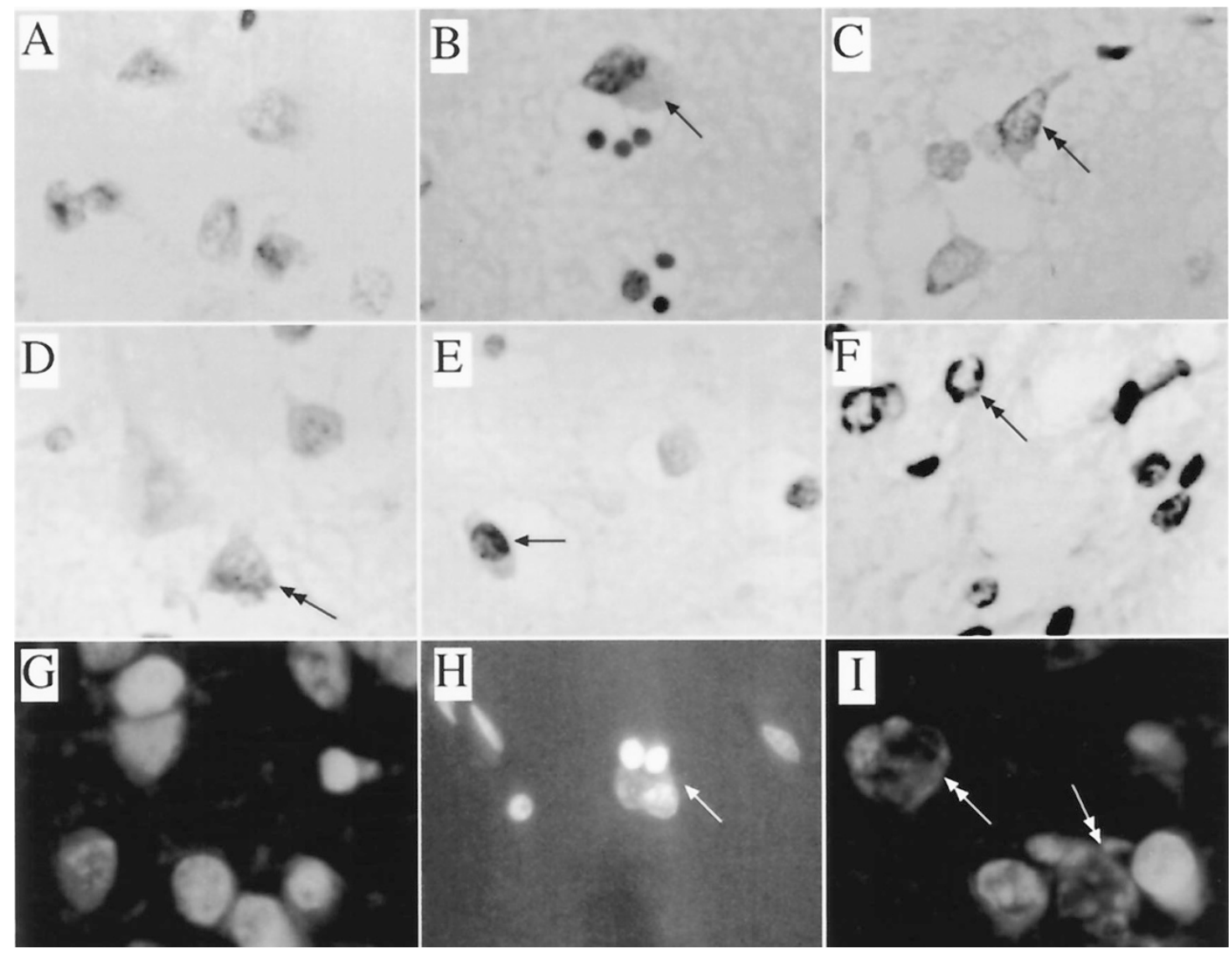

Figure 1 .

Increased DNA fragmentation and nicking in Alzheimer's disease (AD) brains detected by the in situ terminal transferase end-labeling (TUNEL) assay. The $3^{\prime}$ ends of nicked or fragmented DNA were labeled with [14-biotin]dCTP and terminal deoxynucleotide transferase enzyme, and incorporated biotin was detected with horseradish peroxidase conjugated streptavidin and diaminobenzidine. The sections were counterstained with hematoxylin. A, Control cerebral cortex with virtually no labeling. $B$ to $F$, Sections of $A D$ temporal cortex ( $B$ to $D$ ) and underlying white matter ( $E$ and $F$ ) showing increased nuclear only (single-head arrows, $B$ and $E$ ) or nuclear and/or cytoplasmic/perinuclear (double-head arrows, C, D, and F) labeling in neurons (B to D) and glial cells (E and F). D, The neuron in the center exhibits low-level cytoplasmic labeling and absent nuclear labeling, whereas the neuron lower in the field exhibits both nuclear and cytoplasmic TUNEL ${ }^{+}$labeling. G to I, Hoechst H33258 labeling of paraffin-embedded sections demonstrating homogeneous nuclear labeling of control cortical neurons (G), and nuclear fragmentation and condensation in AD cortical neurons (H, arrow). In addition, $\mathrm{H} 33258$ dye labeled cytoplasmic/perinuclear DNA in AD brain neurons (I, double-head arrows).

\section{Increased Mitochondrial DNA Fragmentation in AD}

Successful isolation of MtDNA was verified by agarose gel electrophoresis which demonstrated the expected bands corresponding to Form I, Form II, and Form C (Higuchi and Linn, 1995) in all samples (Fig. 2C). In addition, Southern blot analysis using probes generated with a full-length Mt cDNA (de la Monte and Wands, unpublished data) confirmed that the DNA isolated was indeed mitochondrial in origin (data not shown). Electrophoresis and autoradiography of endlabeled MtDNA revealed $\left[\alpha^{32} \mathrm{P}\right] \mathrm{dCTP}$ incorporation into high molecular weight MtDNA in the AD samples (Fig. 2D). In addition, broadly smeared DNA labeling profiles ranging from approximately $1 \mathrm{kB}$ to $12 \mathrm{kB}$ in size were detected in both $A D$ and control samples, but the intensity of labeling was greater in the $A D$ cases (Fig. 2D). The broadly smeared DNA labeling profiles most likely reflect the presence of multiple random breaks in MtDNA, in contrast to the regular 180 to 200 bp cleavage intervals that occur with GnDNA fragmentation associated with apoptosis. Quantification of $\left[\alpha^{32} \mathrm{P}\right] \mathrm{dCTP}$ incorporated by end- labeling demonstrated that MtDNA fragmentation and nicking were 2- to 3-fold higher in $A D$ than in aged control brains ( $p<0.005$ ) (Fig. 2E).

\section{Reduced Mitochondrial DNA Content in AD}

To determine whether the increased nicking and fragmentation of MtDNA were associated with reduced MtDNA content, the relative abundance of MtDNA was measured by a semiquantitative PCR assay. The PCR products were labeled by incorporation of $\left[\alpha^{32} \mathrm{P}\right] \mathrm{dCTP}$ during amplification. The labeled PCR products were electrophoresed in nondenaturing polyacrylamide gels and analyzed by densitometry (Fig. 3C). To adjust for differences in template loading, the levels of MtDNA measured were normalized with respect to actin DNA amplified in the same samples. Figures $3 \mathrm{~A}$ and $3 \mathrm{~B}$ graphically depict the relative levels (arbitrary densitometry units) of MtDNA measured in individual aged control $(A)$ and $A D(B)$ samples. Figure $3, C$ and $D$, shows the mean $( \pm S D$ ) relative levels of MtDNA in AD and control cases. Note that for most of the AD cases, the MtDNA content was reduced relative to control, 
A

C A A C C C C A A A A C A C C A

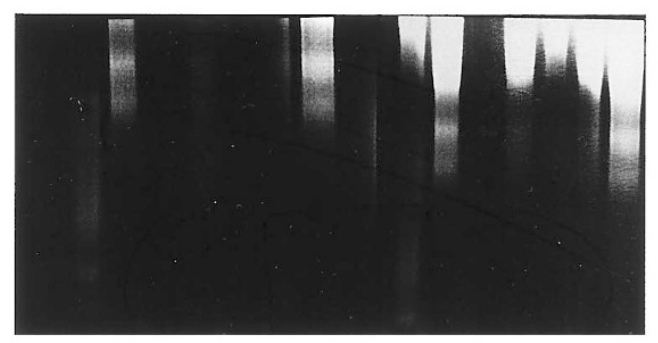

C A A C A C A A C A C

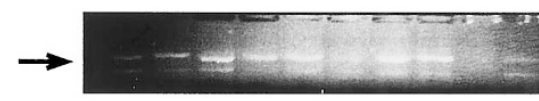

$\mathrm{D}$ A A C A

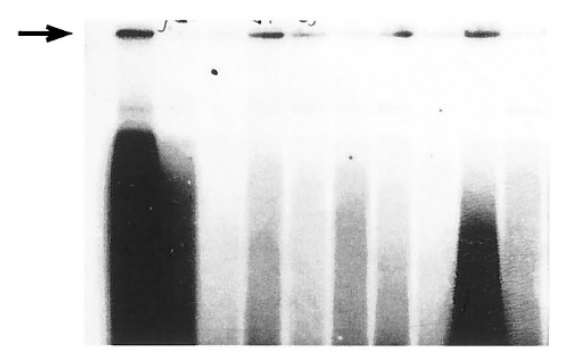

B

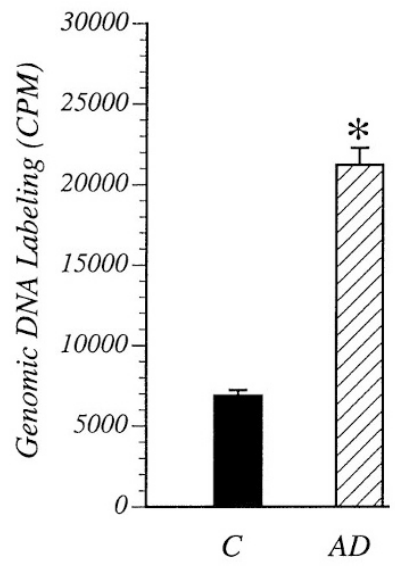

$\mathrm{E}$

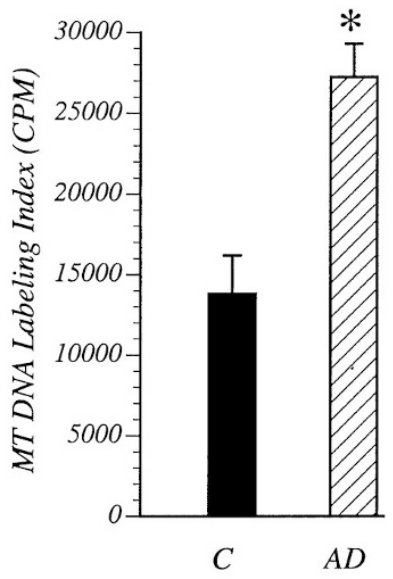

\section{Figure 2.}

Increased fragmentation of genomic and mitochondrial DNA in AD brains. Genomic DNA was extracted from temporal lobe tissue using $7 \mathrm{M}$ guanidine hydrochloride and Wizard DNA resin. A, Samples $(10 \mu \mathrm{g})$ of genomic DNA were electrophoresed in $3 \%$ agarose gels and stained with ethidium bromide. (A, AD; C, control brains.) Only the lower portion of the gel is shown in order to visualize the DNA laddering. The blank-appearing lanes indicate the absence of substantial DNA fragmentation. B, Quantification of genomic DNA fragmentation by solution-based end-labeling. Samples (100 ng) were incubated with [ $\left.{ }^{32} \mathrm{P}\right] \mathrm{dCTP}$ and Klenow DNA polymerase for primer-independent labeling of nicked DNA. [32P]dCTP-incorporation was measured with a scintillation counter. The graph depicts the mean \pm SD CPM/100 ng DNA in control (C) and $\mathrm{AD}$ samples ( ${ }^{*} p<0.001$ by Student $t$ test analysis). Mitochondrial DNA fragmentation was detected by end-labeling. Mitochondrial DNA was extracted from mitochondria that were isolated by sucrose gradient centrifugation. C, High-molecular weight mitochondrial DNA was isolated from both control (C) and AD samples (arrow). The DNA was visualized under UV light after staining with ethidium bromide. Samples (100 $\mathrm{ng})$ were end-labeled [ $\left.{ }^{32} \mathrm{P}\right] \mathrm{dCTP}$ and Klenow DNA polymerase. Ten percent of each sample was analyzed by agarose gel electrophoresis and autoradiography (D), and the degree of [32P]dCTP incorporation was measured using a scintillation counter (E). Note the end-labeled high-molecular-weight mitochondrial DNA (arrow), as well as the broadly smeared signals (2-10 kB) in the $A D$ samples. The broad smears correspond to random breaks in the DNA, in contrast to the regular fragmentation of genomic DNA (A). E, Increased $\left[{ }^{32} \mathrm{P}\right] \mathrm{dCTP}$-incorporation into mitochondrial DNA in AD relative to control samples, confirming the results shown in Panel $\mathrm{D}\left({ }^{*} p<0.005\right.$ by Student $t$ test analysis).

and in more than half the $A D$ samples, the relative MtDNA content was below the 95\% confidence interval limit of the control group $(p<0.001)$. Correspondingly, the mean levels of MtDNA were significantly lower in $A D$ relative to control samples by Student $t$ test analysis ( $T=4.56 ; p<0.001$ ). However, it is noteworthy that several $A D$ cases manifested increased levels of MtDNA, perhaps because of excessive glial cell reaction associated with cell loss, or proliferation of mitochondria in degenerating neurons.

\section{Increased 8-OHdG Immunoreactivity in AD Cortical Neurons}

MtDNA damage can be associated with intramitochondrial accumulation of 8-OHdG (Richter, 1992,
1995). Increased 8-OHdG incorporation into MtDNA can cause base mispairing, random point mutations, and deletions. To determine whether the increased MtDNA fragmentation and nicking in $A D$ could be mediated by this mechanism, we performed immunohistochemical staining of $A D$ and aged control temporal lobe sections to detect 8-OHdG immunoreactivity. However, to exclude inadvertent detection of degraded RNA, the sections were treated with ribonuclease (RNAse) A (100 $\mu \mathrm{g} / \mathrm{ml}$ ) before the primary antibody incubation step. Immunoreactivity was detected by the avidin-biotin horseradish peroxidase complex method using True Blue peroxidase as the substrate. None of the control brains had detectable 8-OHdG immunoreactivity (Fig. 4A), whereas all of the $A D$ cases 


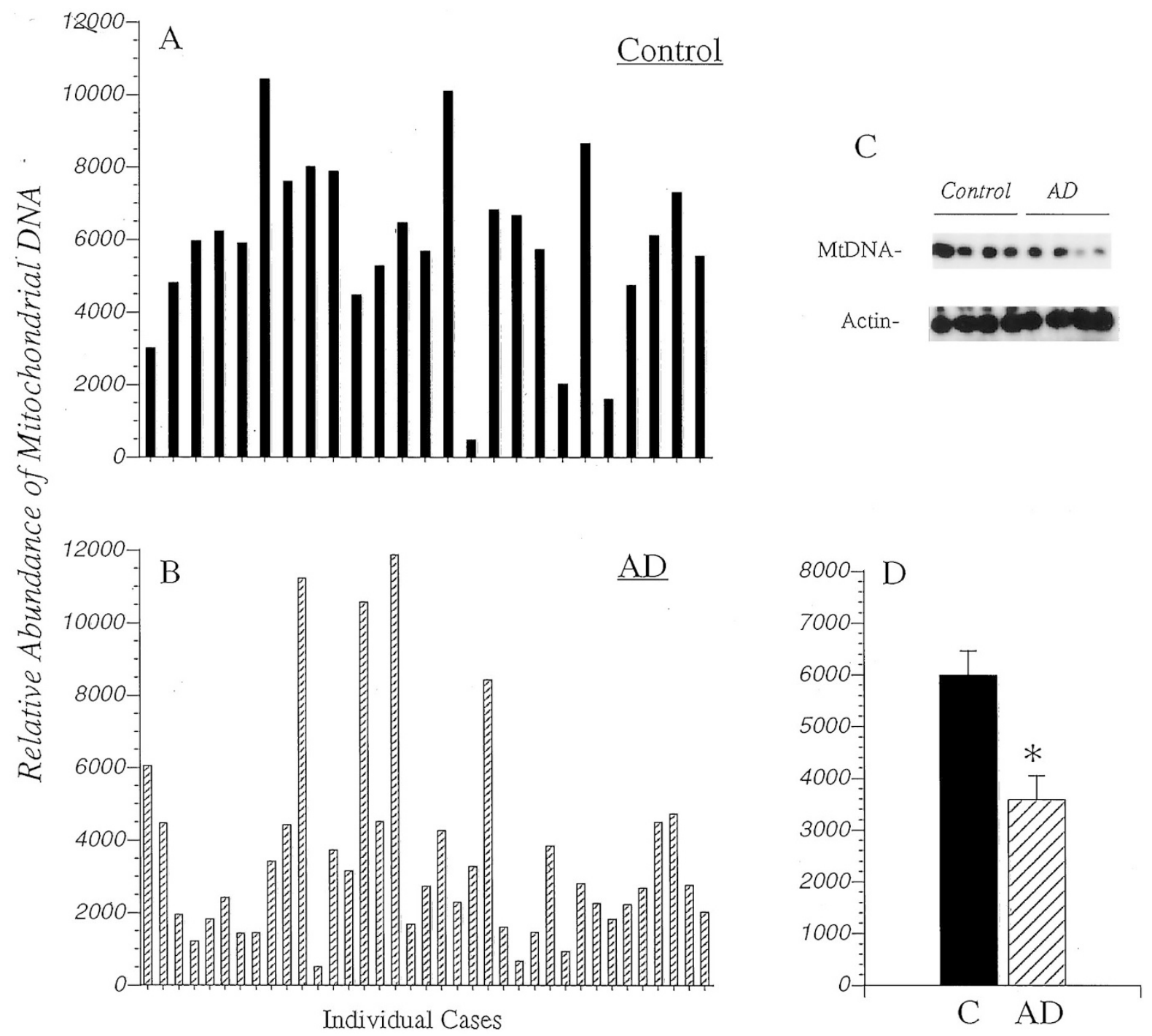

Figure 3.

Reduced mitochondrial DNA abundance in AD brain tissue. Mitochondrial (Mt) DNA was PCR amplified from total DNA extracts. Actin DNA was amplified in separate reactions. $\left[{ }^{32}\right.$ P]dCTP-labeled PCR products were analyzed by electrophoresis, autoradiography, and densitometry. Example PCR products are shown in Panel C. The levels of MtDNA were normalized with respect to the levels of actin DNA to control for differences in target input DNA. The bar graphs in Panels A and B reflect data obtained from individual $A D$ and control cases, and Panel D shows the mean \pm SEM of the levels (arbitrary densitometry units). The difference between the mean levels of MtDNA in AD and control cases is statistically significant by Student $t$ test analysis $(p<0.001)$.

exhibited 8-OHdG immunoreactivity in scattered cortical neurons (Fig. 4, B and C). Pretreatment of the sections with deoxyribonuclease (DNAse) I (20 $\mu \mathrm{g} / \mathrm{ml}$ ) abolished the 8-OHdG immunoreactivity (Fig. 4D), indicating that the 8-OHdG molecules were incorporated into DNA.

\section{Reduced Mitochondrial Mass in AD}

To determine whether the increased MtDNA fragmentation was associated with reduced mitochondrial mass in $A D$, mitochondrial protein expression and MitoTracker Green fluorescence labeling were analyzed. Mitochondrial protein was detected by Western blot analysis and immunohistochemical staining using monoclonal antibodies that were generated to human mitochondria. Although the anti- body immunoreacts with an uncharacterized protein, a single approximately $65 \mathrm{kD}$ species is detected by Western blot analysis, and the immunoreactivity is characterized as a beaded or granular profile that is typical of mitochondria and identical to the labeling patterns observed with antibodies to cytochrome oxidase, complex IV (COX) and with the MitoTracker Green FM dye.

Densitometric analysis of the Western blot autoradiographs revealed significantly lower mean levels of mitochondrial protein in $A D$ relative to control brains $(p<0.001)$ (Fig. 5). Immunohistochemical staining of formalin-fixed, paraffin-embedded tissue sections revealed abundant coarse granular staining of neuronal perikarya and neuropil fibers in aged control brains, and strikingly reduced levels of mitochondrial protein immunoreactivity in $A D$ cortical and hippocampal 


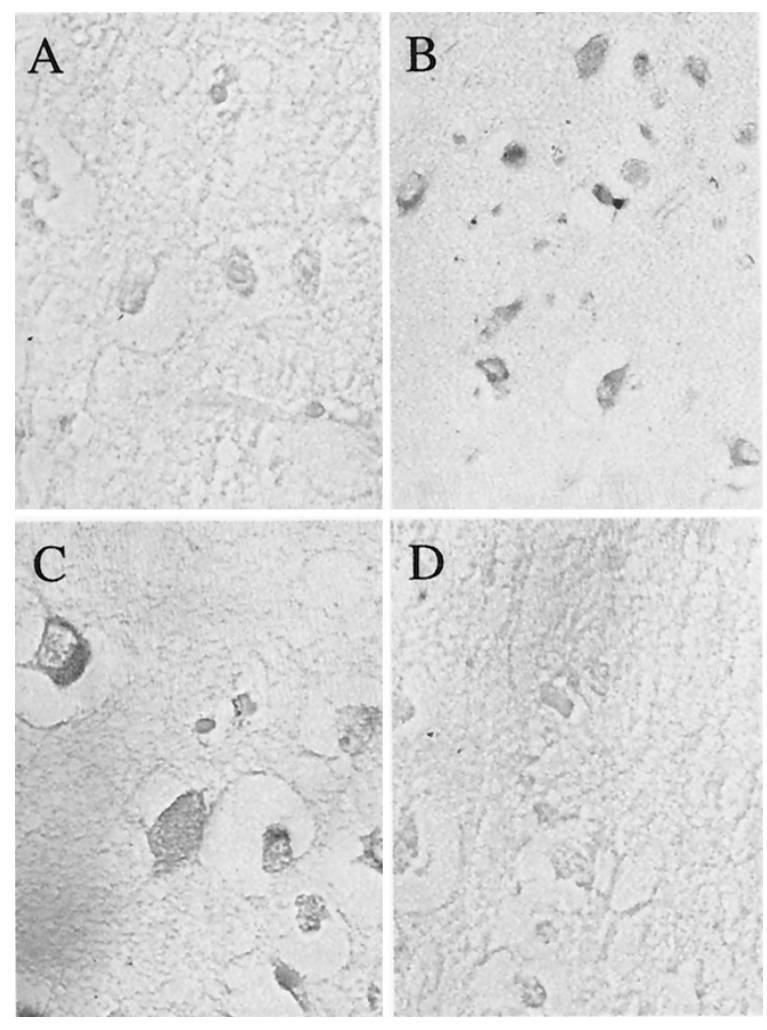

\section{Figure 4.}

Increased 8-hydroxy-deoxyguanosine (8-OHdG) immunoreactivity in $\mathrm{AD}$ cortical neurons. Sections of control $(A)$ and $A D(B$ to $D)$ temporal cortex were immunostained with antibodies to $8-0 \mathrm{HdG}$. Immunoreactivity was detected using the $A B C$ method and TrueBlue peroxidase as the chromogen (blue precipitate). The sections were counterstained with Nuclear Fast Red. Before the primary antibody incubation step, the sections were treated with ribonuclease (RNAse) A (100 $\mu \mathrm{g} / \mathrm{ml})$ to avoid detecting 8-OHdG incorporated into RNA. Control brains exhibited virtually no 8-OHdG immunoreactivity (A) whereas in $A D$, scattered cortical cells (mainly neurons) displayed increased 8-OHdG immunoreactivity (B). C, Cellular 8-OHdG labeling in AD at higher magnification. D, To verify 8-OHdG incorporation into DNA, adjacent sections were also pretreated with deoxyribonuclease (DNAse) I $(20 \mu \mathrm{g} / \mathrm{ml})$. D, Shows abolishment of 8-OHdG immunoreactivity following DNAse I pretreatment of a section adjacent to the one illustrated in Panel C.

(CA1 and CA2) neurons and neuropil fibers (Fig. 6, A and $\mathrm{B}$ ). Reduced mitochondrial mass/abundance in $A D$ brain neurons was further demonstrated by labeling adjacent sections with MitoTracker Green FM dye (Molecular Probes, Eugene, Oregon). MitoTracker Green is a mitochondria-specific fluorescent dye that labels fixed mitochondria and is used to assess mitochondrial mass. MitoTracker Green fluorescence was observed in all cell types, but the labeling was most conspicuous in neuronal perikarya and cell processes. The main difference between $A D$ and control brains was that in $A D$, the intensity of labeling in neurons was strikingly reduced (Fig. 6, C and D), particularly in cortical Layers 5 and 6 where neurofibrillary tangles abounded. However, neuronal labeling in AD was heterogeneous, rather than uniformly reduced, in that scattered individual and small clusters of five to seven cortical neurons exhibited intense levels of mitochondrial protein immunoreactivity or MitoTracker Green fluorescence (data not shown).

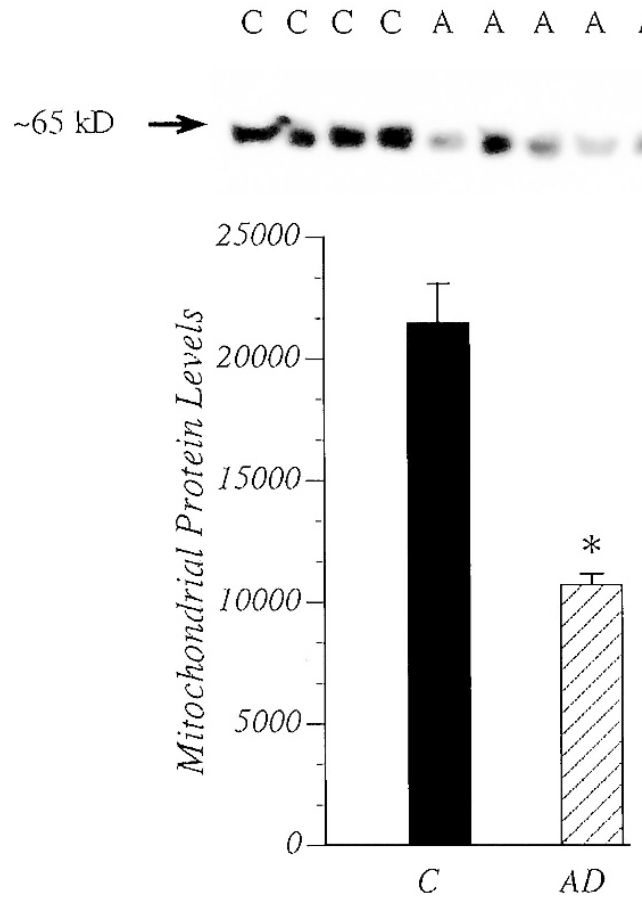

Figure 5.

Reduced levels of mitochondrial protein expression in AD. Western blot analysis was performed using temporal lobe extracts and monoclonal antibodies to mitochondrial protein. An example Western blot autoradiograph demonstrates the approximately $65 \mathrm{kD}$ band corresponding to mitochondrial protein in both $A D(A)$ and control $(C)$ samples. The levels of mitochondrial protein were measured by densitometry (arbitrary units), and the mean \pm SD levels for each group are depicted in the graph $\left({ }^{\star} p<0.001\right.$ by Student $t$ test analysis).

\section{Reduced COX Expression in AD Cortical Neurons}

To determine whether the increased MtDNA fragmentation and reduced mitochondrial mass were associated with reduced expression of a mitochondriaspecific protein in $A D$, temporal lobe sections were immunostained with monoclonal antibodies to COX, Complex IV. Aged control brains exhibited abundant coarse granular staining of neuronal perikarya and neuropil fibers (Fig. 7, A to C). Corresponding with the patterns of mitochondrial protein immunoreactivity and MitoTracker Green fluorescence labeling, neurons in cortical Layers 5 and 6 and in the CA1 and CA2 regions of the hippocampus exhibited the most intense and abundant COX immunoreactivity in control brains. In AD, the density of COX-positive neurons and the intensity of the COX immunostaining reaction in neurons and neuropil fibers were reduced relative to controls, and many cortical neurons exhibited little or no COX immunoreactivity (Fig. 7, D to F). However, corresponding with the mitochondrial protein and MitoTracker Green labeling studies, scattered individual and small clusters of cortical neurons in AD manifested intense levels of COX immunoreactivity, suggesting heterogeneity in neuronal COX expression with $\mathrm{AD}$ neurodegeneration.

To further characterize the heterogeneous nature of COX expression in AD brains, we used image analysis to determine the percentage of cells in the cerebral 

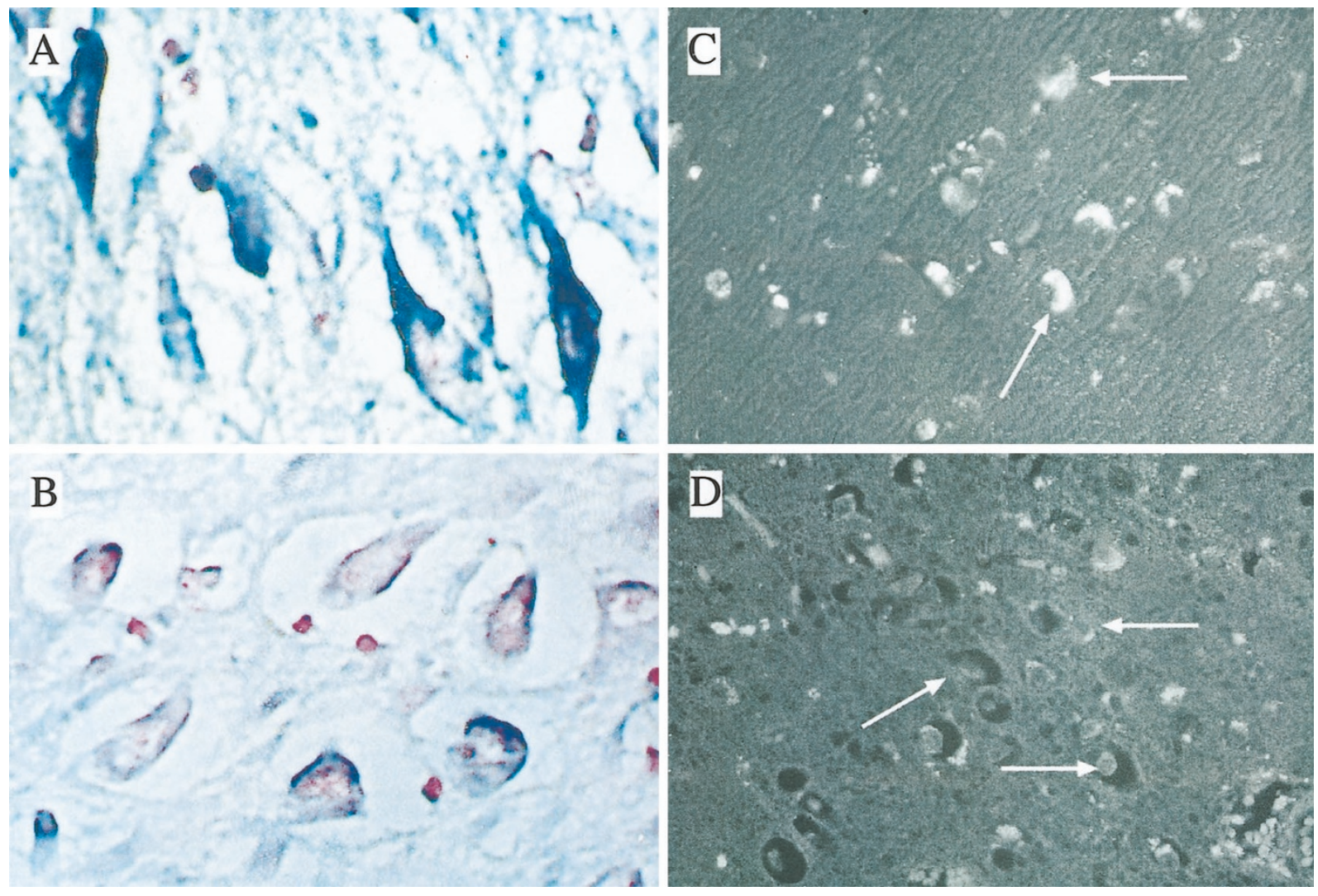

\section{Figure 6 .}

Reduced levels of mitochondrial protein immunoreactivity and MitoTracker Green fluorescence of AD cortical neurons. Paraffin sections of temporal neocortex were immunostained with monoclonal antibody to mitochondrial protein. Immunoreactivity was revealed by the avidin-biotin-alkaline phosphatase method using nitro blue tetrazolium/5-bromo-4-chloro-3-indolyl phosphate (NBT/BCIP) as the chromogen. A, Control temporal cortex showing abundant labeling of neuronal perikarya and neuropil fibers. B, AD temporal cortex showing reduced labeling of neurons and neuropil fibers. Adjacent sections were labeled with MitoTracker Green dye, which localizes in mitochondria. The sections were examined by fluorescence microscopy using a fluorescein filter. Corresponding with the results shown in Panels A and $\mathrm{B}$, control brains exhibited bright MitoTracker Green fluorescence in most cortical neurons ( $\mathrm{C}$, arrows), whereas most AD cortical neurons displayed reduced levels of MitoTracker green fluorescence (D, arrows).

cortex that could be classified as COX-positive $(++)$, COX-low-level $(+)$, or COX-negative (-) (Figs. 7 and 8). Since the qualitative assessments suggested that in $A D, C O X$ immunoreactivity was reduced mainly in the deeper cortical layers, we quantified the relative densities of cells exhibiting,+++ , or $-\mathrm{COX}$ immunoreactivity within Layers 1 to 4 and Layers 5 to 6 . Using the overall percentages of $\mathrm{COX}++,+$, or - cells in 20 adjacent $\times 200$ magnification fields that spanned the full-thickness of the regions of interest, the $A D$ and control group means \pm SDS were calculated, and statistical comparisons were made using ANOVA with the Fisher Least Significant Difference (LSD) post hoc test. The cases were analyzed under code. As illustrated in Figure 8 , approximately $80 \%$ of control cells within Layers 1 to 4 had ++ or + COX immunoreactivity, and within Layers 5 and 6, approximately $90 \%$ of the cells had ++ or + levels of COX expression. In $A D$, approximately $75 \%$ of the cells in cortical Layers 1 to 4 had ++ or + COX expression, and approximately $70 \%$ of the cells in Layers 5 and 6 manifested ++ or + COX expression $(p<0.001)$. More specifically, the brains with $A D$ had significantly lower densities of cells with ++ COX expression throughout the cortex $(p<0.001)$, and significantly increased densities of COX-negative cells in Layers 1 to $4(p<0.05)$ and Layers 5 and $6(p<0.001)$ (Fig. 8). In $A D, 28 \%$ of the cells in cortical Layers 5 and 6 were COX-negative, compared with $9 \%$ in control brains $(p<0.001)$. Although we did not attempt to classify the populations of COX-negative and COX-positive cells, the size ( $>6 \mu \mathrm{m}$ diameter) and shape (not round) threshold criteria used for image analysis resulted in the inclusion of predominantly neurons (pyramidalshaped and bearing a nucleolus).

\section{Discussion}

This study demonstrates that brains with $A D$ neurodegeneration exhibit increased fragmentation of MtDNA, reduced MtDNA content, increased 8-OHdG immunoreactivity, and reduced levels of mitochondrial protein, COX immunoreactivity, and MitoTracker Green fluorescence. End labeling assays detected the increased MtDNA fragmentation, and semiquantitative PCR studies showed that MtDNA content was reduced in $A D$. The increased levels of $8-O H d G$ immunoreactivity in $A D$ cortical neurons is consistent with the finding of 


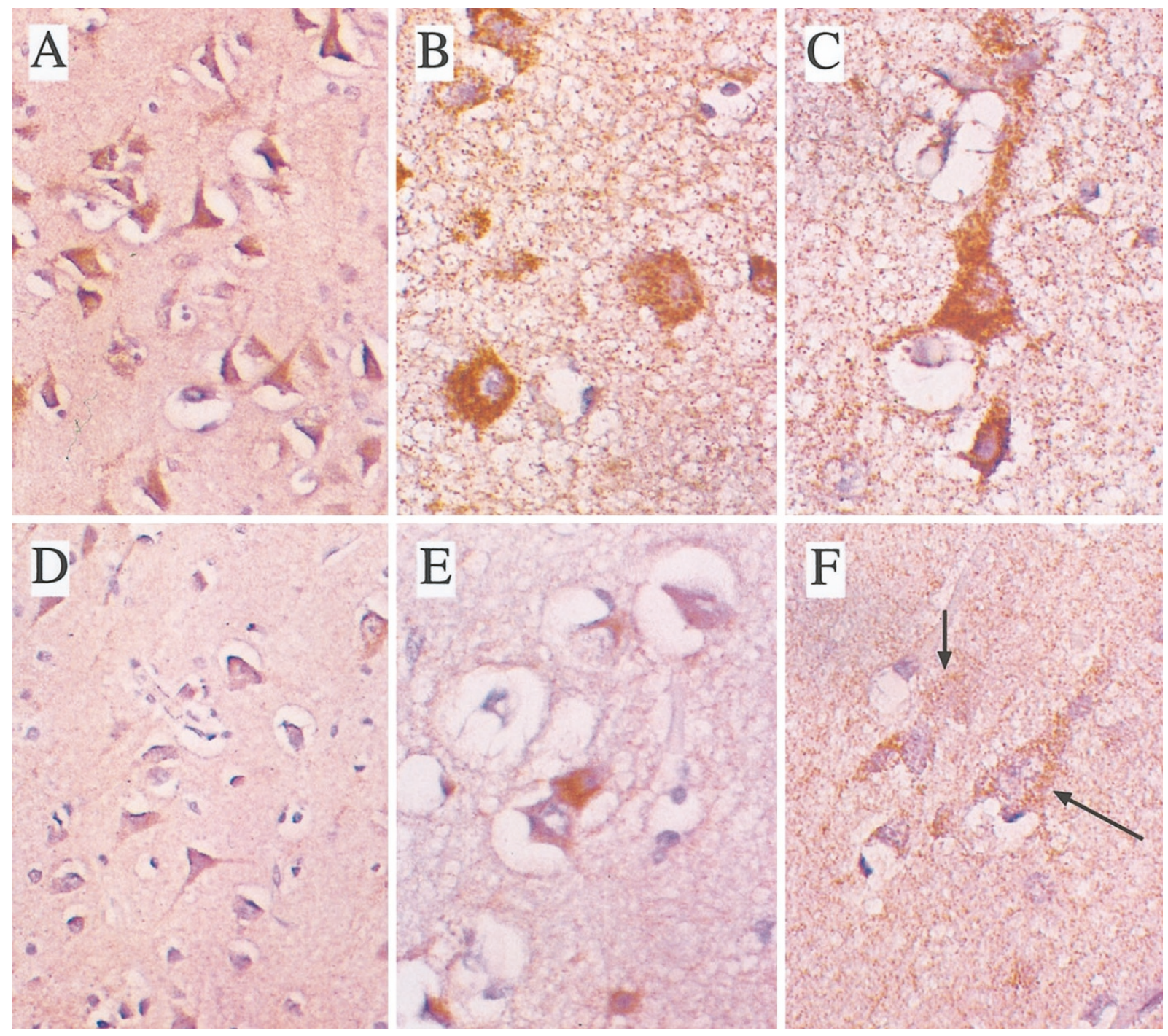

\section{Figure 7.}

Reduced levels of cytochrome oxidase (COX) immunoreactivity in AD temporal cortex. Paraffin sections of temporal neocortex were immunostained with monoclonal antibody to COX, Complex IV. Immunoreactivity was revealed by the ABC method using diaminobenzidine as the chromogen and hematoxylin as the counterstain. A to $\mathrm{C}$, Control brains exhibited prominent COX immunoreactivity in most cortical neurons and within the neuropil fibers. Note the granular quality of the immunostaining reaction. $\mathrm{D}$ to $\mathrm{F}$, In $\mathrm{AD}, \mathrm{COX}$ immunoreactivity was strikingly reduced in both neurons and neuropil fibers. In Panels $\mathrm{E}$ and $\mathrm{F}$, negative or markedly reduced COX immunoreactivity is depicted in large pyramidal neurons. Panel F show examples (arrows) of distinct pyramidal neurons with low levels (+) of COX immunoreactivity.

increased MtDNA damage as demonstrated by the TUNEL assay and end-labeling of isolated MtDNA. Increased MtDNA damage and reduced MtDNA content in $A D$ were associated with reduced expression of mitochondrial protein and COX, and reduced MitoTracker Green labeling. Although reduced COX expression in $A D$ has been reported previously (Chandrasekaran et al, 1998; Nagy et al, 1999; Wong-Riley et al, 1997), the present study provides new information indicating that in $A D$, impaired mitochondrial function with reduced expression of mitochondriaencoded genes is likely caused by MtDNA damage. In addition, enhanced MtDNA damage results in reduced mitochondrial mass (mitochondrial protein expression, MitoTracker Green labeling) and reduced MtDNA content. Therefore, this study provides evidence for dual mechanisms of cell loss in $A D$, namely apoptosis and
MtDNA damage with impaired mitochondrial function. The reduced levels of mitochondrial protein and COX immunoreactivity in AD neuropil fibers further suggest that impaired energy metabolism may contribute to the neuritic and synaptic pathology that correlates with dementia.

The semiquantitative PCR studies demonstrated increased MtDNA content in 4 of the 37 AD cases (Fig. 4). In addition, the in situ studies demonstrated marked heterogeneity in neuronal labeling in brains with AD. Heterogeneous labeling was characterized by the presence of many neurons with reduced or undetectable mitochondrial protein or COX immunoreactivity and MitoTracker Green fluorescence, and scattered individual or small clusters of neurons with prominent labeling that was similar to or greater than in control brains, consistent with previous observa- 


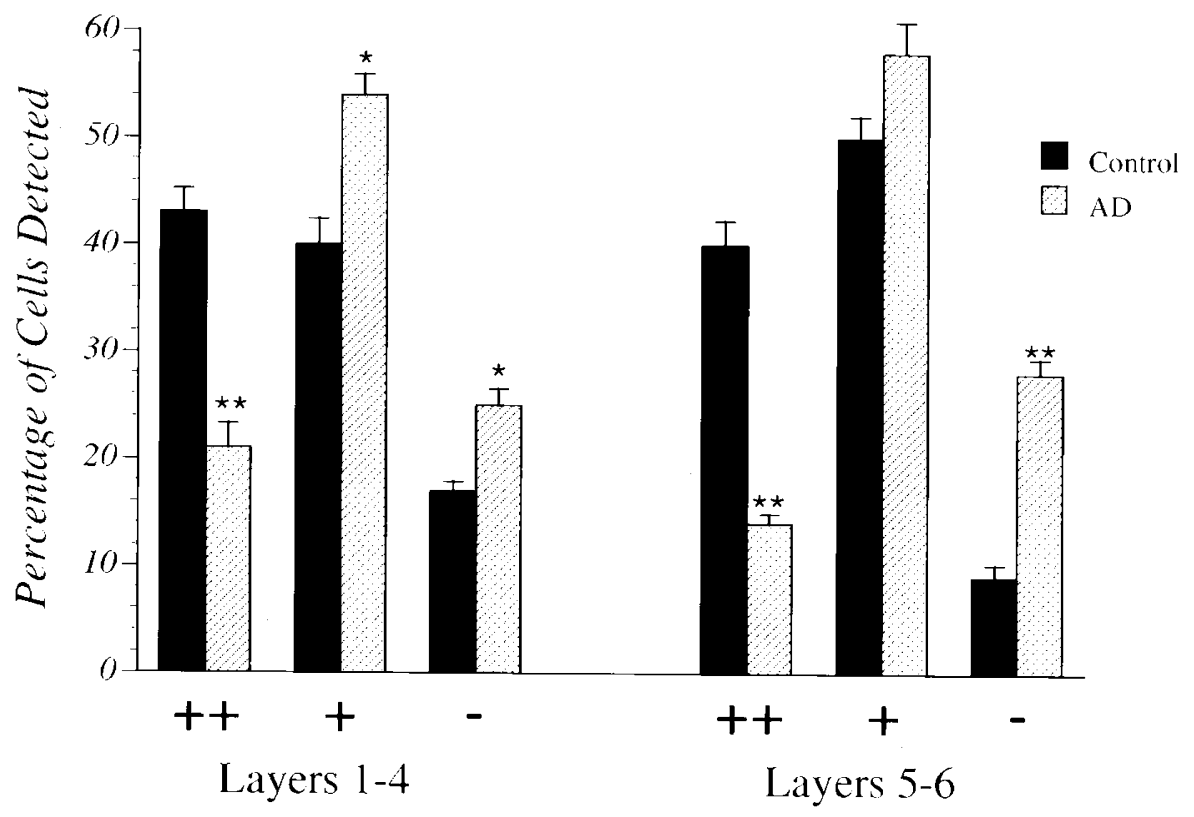

\section{Figure 8.}

Reduced levels of COX expression in $\mathrm{AD}$ demonstrated by image analysis. COX-immunostained sections of temporal lobe were used to determine the percentages of cells with abundant $(++)$, low-level $(+)$ or absent $(-)$ COX immunoreactivity distributed in cortical Layers 1-4 and Layers 5 and 6 . For each case, 20-200X adjacent fields spanning the full-thickness of the region were examined (see "Materials and Methods" section). The neuron in Figure $7 \mathrm{C}$ (center) illustrates $++\mathrm{COX}$ immunoreactivity. The neurons in Figure 7F show + COX immunoreactivity. The graphed data depict the group means \pm SDS corresponding to the percentages of cells within each category. Intergroup comparisons were made using ANOVA and the Fisher LSD post hoc significance test $\left({ }^{\star} p<0.05 ;{ }^{\star \star} p<0.001\right)$.

tions (Nagy et al, 1999). One possible explanation for the paradoxically increased mitochondrial mass (abundance), mitochondrial gene expression, and MtDNA content observed in small populations of $A D$ brain neurons is that, during the early stages of MtDNA damage, cellular responses can include compensatory proliferation of mitochondria. Therefore, heterogeneity in neuronal levels of MtDNA, mitochondrial protein, and mitochondrial enzyme gene expression in $A D$ could reflect variability in the stages of neurodegeneration.

This study also demonstrated increased GnDNA damage in AD. GnDNA damage was associated with fragmentation laddering and approximately 3-fold higher levels of $\left[\alpha-{ }^{32} \mathrm{P}\right] \mathrm{dCTP}$ incorporation using an end-labeling assay. Although GnDNA laddering may not be specific for apoptosis, it probably does correspond to apoptosis in $A D$ because the density of TUNEL $^{+}$condensed nuclei (de la Monte et al, 1997, 1998), and the levels of proapoptosis, eg, p53, CD95, and Bax (de la Monte et al, 1997, 1998; Su et al, 1997; Tortosa et al, 1998), stress-responsive (Stadelmann et al, 1998) gene expression, and caspase activity (Desjardins and Ledoux, 1998; Ivins et al, 1999; Kitamura et al, 1998) are also increased. An important direction for future research will be to determine the preexisting and acquired abnormalities that are responsible for activating apoptosis cascades and rendering central nervous system cells more susceptible to oxygen-free-radical injury in the context of neurodegeneration.

There are several candidate genes and molecules that may contribute to or be responsible for the heightened susceptibility to apoptosis in $A D$. The accumulation of $A \beta$-amyloid in brains with $A D$ may be important in this regard because increased levels of Bax and p53 immunoreactivity have been localized within and around $\mathrm{A} \beta$-amyloid deposits in senile plaques (de la Monte et al, 1997, 1998; Su et al, 1997; Tortosa et al, 1998). Experimentally, $A \beta$-amyloid has been shown to be neurotoxic or to induce proapoptosis and inhibit cell survival gene expression (Davis et al, 1999; Forloni et al, 1996; Giambarella et al, 1997; Gunn-Moore and Tavare, 1998; Ivins et al, 1999; Paradis et al, 1996; Prehn et al, 1996; Sayre et al, 1997a; Yamatsuji et al, 1996) and activate oxidative stress-related genes (Pappolla et al, 1998). Moreover, $\mathrm{A} \beta$-amyloid-induced cellular degeneration can be rescued or prevented by treatment with antioxidant or free-radical scavenger agents (Prehn et al, 1996). Together, these observations suggest that $A \beta$-amyloid deposits in the brain may indirectly contribute to cell loss in $A D$ because of the activation of proapoptosis genes. Of interest is the fact that only some $A \beta$ amyloid deposits were surrounded by p53- or Baximmunoreactive fibrils (de la Monte et al, 1997; Su et al, 1997; Tortosa et al, 1998), suggesting that other factors might be required to link $A \beta$-amyloid to neurodegeneration.

Nitric oxide synthase-3 (NOS-3) (de la Monte and Bloch, 1997) and hemeoxygenase-1 (HO-1) (Premkumar et al, 1995) represent two genes that are aberrantly expressed in $A D$, and whose gene products, when present in excess amounts can enhance cellular susceptibility to oxidative stress and free-radical injury. NOS activity generates nitric oxide (NO) (Schmidt 
and Walter, 1994), which at physiological levels can mediate important neuronal functions. However, overexpression of NOS can lead to the generation of $\mathrm{H}_{2} \mathrm{O}_{2}$, $\mathrm{OH}-$, and superoxides (Leist et al, 1997; Pou et al, 1992; Stamler, 1994; Xia et al, 1996), which promote DNA damage and neuronal cell death. Aberrantly increased NOS-3 expression has been linked to neurodegeneration in $A D$ and other diseases (de la Monte and Bloch, 1997; Sohn et al, 1999).

$\mathrm{HO}-1$ is an inducible microsomal enzyme that oxidatively cleaves heme, a pro-oxidant, to biliverdin, an antioxidant, and carbon monoxide, a potential neurotransmitter. Reduced HO-1 activity can result in accumulation of heme, whereas increased $\mathrm{HO}-1$ activity can cause increased levels of $\mathrm{CO}$, and possibly excitotoxic death of neurons (Maines, 1988). Previous studies demonstrated increased levels of $\mathrm{HO}-1$ mRNA and immunoreactivity in AD (Premkumar et al, 1995; Schipper et al, 1995). Since heme is a critical substrate for NO production, excessive oxidative cleavage of heme by $\mathrm{HO}-1$ could encourage the generation of reactive oxygen species in cells with aberrantly increased levels NOS activity. Importantly, $\mathrm{HO}-1$ and NOS expression can be colocalized in the same cells and induced by the same stimuli (Durante et al, 1997; Kurata et al, 1996; Seki et al, 1997). Therefore, the aberrantly increased expression of NOS-3 and HO-1 in AD could contribute to increased cellular susceptibility to oxidative stress and free-radical injury to MtDNA.

MtDNA fragmentation in AD was associated with a broad size range of end-labeled molecules, consistent with the occurrence of multiple random breaks rather than specific mutations or deletions. The finding that aged control brains also showed some degree of MtDNA fragmentation is consistent with previous reports that demonstrated progressive age-associated oxidative MtDNA damage and intra-mitochondrial accumulation of 8-OH-dG (Richter, 1992, 1995). However, since the degrees of MtDNA fragmentation and 8-OHdG immunoreactivity were higher in $A D$ relative to control samples, it is unlikely that aging alone could have accounted for the excessive MtDNA damage associated with AD. In this regard, aberrant expression of NOS-3 and $\mathrm{HO}-1$ may represent important mediators of oxidative free-radical damage to MtDNA and mitochondria.

The reduced levels of mitochondrial protein, COX, and MitoTracker Green labeling in AD suggest that $A D$ neurodegeneration is associated with reductions in mitochondrial mass (abundance) and function. Impaired mitochondrial function could be attributed to depletion of mitochondria and increased MtDNA damage with attendant disruption of mitochondrial gene expression. Impaired mitochondrial function could render neurons more vulnerable to apoptosis mediated by oxidative stress and free-radical injury. Since the distribution and abundance of mitochondria are critical for cell function, the reduced levels of mitochondrial protein and COX immunoreactivity in neuropil fibers in $A D$ may reflect impaired dendritic function and synaptic maintenance required for learning and memory. These observations support the hypothesis that $A D$ neurodegeneration can be precipitated and propagated by free-radical injury, and therefore also could be prevented or delayed by free-radical scavenger or antioxidant therapy.

\section{Materials and Methods}

\section{Source of Tissue and Population Profile}

The brains were harvested within 18 hours of death according to the Massachusetts General Hospital Alzheimer's Disease Research Center protocol (de la Monte, 1989). The AD group $(n=37)$ had a mean age of $76.3 \pm 8.8$ years, brain weight of $1117 \pm 101$ grams, and postmortem interval of $7.3 \pm 3.9$ hours. The control group $(n=25)$ had a mean age of $78.0 \pm$ 6.2 years, brain weight of $1274 \pm 115$ grams, and postmortem interval of $8.3 \pm 3.6$ hours. The immediate causes of death were similar for the two groups, with most patients succumbing to pneumonia (bacterial or aspiration) or cardiac arrest. Histopathologic diagnoses were established using paraffin-embedded sections stained with Luxol fast blue, hematoxylin, and eosin, Bielschowsky silver impregnation, and Congo red. The diagnosis of definite $A D$ was rendered using the criteria established by the Consortium to Establish a Registry for Alzheimer's Disease (CERAD) and Braak and Braak (Esiri and Morris, 1997).

\section{Isolation of DNA}

DNA was isolated from temporal lobe tissue. To isolate genomic and MtDNA from the same samples, the brain tissue was dounce homogenized in buffer containing $10 \mathrm{~mm}$ Tris, $\mathrm{pH}$ 7.5, $50 \mathrm{~mm} \mathrm{NaCl}$, and $0.25 \mathrm{M}$ sucrose. Nuclei were pelleted by centrifuging the samples at $5000 \times g$ for 15 minutes at $4^{\circ} \mathrm{C}$. Mitochondria present in the supernatant fraction were pelleted through a sucrose cushion and then digested with 50 $\mu \mathrm{g} / \mathrm{ml}$ DNAse-free RNAse A followed by $250 \mu \mathrm{g} / \mathrm{ml}$ of proteinase K (Ausubel et al, 1998). MtDNA was extracted with Wizard Maxiprep resin and concentrated by ethanol precipitation (Ausubel et al, 1998). Genomic DNA was isolated from the nuclear pellets using $7 \mathrm{M}$ guanidine $\mathrm{HCl}$ and Wizard Maxi-prep resin (Promega, Madison, Wisconsin) according to the manufacturer's protocol. DNA concentrations were determined from the absorbances measured at $260 \mathrm{~nm}$ and $280 \mathrm{~nm}$.

\section{Detection of DNA Fragmentation}

Apoptosis and DNA fragmentation or nicking were detected by agarose gel electrophoresis, primerindependent incorporation of $\left[\alpha^{-32} \mathrm{P}\right] \mathrm{dCTP}$, Hoechst's H33258 staining, and the TUNEL assay. To visualize DNA fragmentation ladders, $10 \mu \mathrm{g}$ samples of GnDNA were electrophoresed in 3\% agarose gels. The DNA was stained with ethidium bromide and visualized with ultraviolet illumination. The degrees of DNA fragmentation or nicking were assessed by measuring $\left[\alpha^{-}{ }^{32} \mathrm{P}\right] \mathrm{dCTP}$ incorporation into purified GnDNA or 
MtDNA in reactions devoid of oligonucleotide primers (Moyse and Michel, 1997). Briefly, duplicate $100 \mathrm{ng}$ DNA samples were incubated for 15 minutes at $22^{\circ} \mathrm{C}$ in $20 \mu$ reactions containing $1 \times$ Klenow buffer, $1 \mathrm{U}$ Klenow DNA polymerase, and $0.2 \mu \mathrm{Ci}$ of $\left[\alpha^{-32} \mathrm{P}\right] \mathrm{dCTP}$. Labeled DNA was isolated using Wizard DNA Clean-up resin (Promega), and $\left[\alpha-^{32} \mathrm{P}\right] \mathrm{dCTP}$ incorporation was measured in a scintillation counter. This protocol permits simultaneous quantification of DNA damage in multiple samples. The pattern of MtDNA fragmentation was observed by agarose gel electrophoresis and autoradiography of end-labeled samples.

The TUNEL assay was used to detect nicked or fragmented DNA in formalin fixed, paraffin-embedded sections of the temporal lobe. The reactions were performed using [14-biotin]dCTP (Gibco-BRL, Grand Island, New York) and terminal deoxynucleotide transferase (de la Monte et al, 1997), and biotin-labeled DNA was detected with horseradish peroxidase conjugated streptavidin and diaminobenzidine. Adjacent sections were stained with Hoechst H33258 $(1 \mu \mathrm{g} / \mathrm{ml}$ in PBS) for 2 minutes at room temperature. The slides were rinsed thoroughly in PBS, cover-slipped with Vectashield mounting medium (Vector Laboratories, Burlingame, California), and examined by fluorescence microscopy.

\section{Determination of Relative Abundance of Mitochondrial DNA}

To determine whether the increased nicking and fragmentation of MtDNA were associated with reduced MtDNA content, the relative abundance of MtDNA was measured by a semiquantitative PCR assay. Briefly, total DNA was extracted from tissue using $7 \mathrm{M}$ guanidine $\mathrm{HCl}$ and Wizard Maxiprep DNA resin (Promega) according to the manufacturer's protocol. Samples containing $1 \mu \mathrm{g}$ DNA were analyzed by PCR using the following primers that amplify a $235 \mathrm{bp}$ sequence of MtDNA (forward: 5'-ATTTCGTACATTACTG; reverse: 5'-TGTGCTATGTACGGTAAATG) (Hauswirth et al, 1994). Actin DNA was co-amplified using a primer set that generated a 568 bp fragment (forward: 5'ATGGATGACGATATCGCTG; reverse: 5'ATGAGGTAGTCTGTCAGGT). Each $50 \mu \mathrm{l}$ reaction contained $1 \times$ PCR buffer, $200 \mu \mathrm{M}$ deoxyribonucleoside triphosphate, $2.5 \mu \mathrm{M} \mathrm{MgCl}_{2}, 100$ pmol of each primer, $1 \mu \mathrm{Ci}$ of $\left[\alpha^{32} \mathrm{P}\right] \mathrm{dCTP}$, and $1 \mathrm{U}$ of Taq polymerase. After 5 minutes denaturation at $95^{\circ} \mathrm{C}$, the samples were amplified with 15 cycles of 1 minute at $95^{\circ} \mathrm{C}, 2$ minutes at $56^{\circ} \mathrm{C}$, and 1 minute at $72^{\circ} \mathrm{C}$. Preliminary studies demonstrated linear amplification of both MtDNA and actin DNA with fewer than 20 PCR cycles. The reaction products were electrophoresed in $4 \%$ nondenaturing polyacrylamide gels and analyzed by autoradiography. The levels of MtDNA and actin DNA were measured by volume densitometry using National Institutes of Health Image software. The levels of MtDNA were normalized with respect to actin DNA to adjust for differences in template abundance.

\section{Assessments of Mitochondrial Mass}

Mitochondrial mass was evaluated by labeling formalin-fixed, paraffin-embedded tissue sections with MitoTracker Green FM dye (Molecular Probes). After deparaffinization and rehydration through graded ethanol solutions, the sections were incubated (30 minutes, room temperature) with MitoTracker Green FM diluted 1:5000 in PBS. The sections were rinsed in 3 changes of PBS, cover-slipped with Vectashield mounting medium (Vector Laboratories), and examined by fluorescence microscopy using a fluorescein filter.

\section{Analysis of Mitochondrial Protein Expression}

Mitochondrial protein expression was examined by Western blot analysis and immunohistochemical staining using the MAB1273 monoclonal antibody to human mitochondrial protein (Chemicon International Inc., Temecula, California). Homogenates of fresh frozen temporal lobe tissue (de la Monte and Bloch, 1997; de la Monte et al, 1997) were used for Western analysis (Ausubel et al, 1998). The tissues were homogenized in buffer containing Triton lysis buffer (Ausubel et al, 1998), and insoluble cellular components were removed by centrifuging the samples at $15000 \times g$ for 30 minutes. Samples containing $100 \mu \mathrm{g}$ of protein were electrophoresed in $10 \%$ sodium dodecyl sulfate-polyacrylamide gels under denaturing and reducing conditions along with prestained molecular weight standards (Gibco-BRL) (Ausubel et al, 1998). Proteins transferred to Immobilon-P membranes (Millipore Corporation, Bedford, Massachusetts) were probed with $1 \mu \mathrm{g} / \mathrm{ml}$ of antimitochondrial antibody. Antibody binding was detected with horseradish peroxidase-conjugated secondary antibody (lgG) and enhanced chemiluminescence reagents (Pierce Chemical Company, Rockford, Illinois). Mitochondrial protein levels were quantified by densitometric scanning of nonsaturated autoradiographs using NIH Image Software, v 1.6. Protein concentrations were determined using the bicinchoninic acid assay (Pierce Chemical Company).

\section{In Situ Analysis of Mitochondrial Protein and COX Protein Expression}

The cellular distributions of mitochondrial protein and COX (Complex IV) expression were examined by immunohistochemical staining of formalin-fixed, paraffin-embedded sections of the temporal lobe. The sections were dewaxed, rehydrated, treated with $0.6 \%$ hydrogen peroxide in $60 \%$ methanol to quench endogenous peroxidase activity and then blocked with normal horse serum. The sections were incubated overnight at $4^{\circ} \mathrm{C}$ with $1 \mu \mathrm{g} / \mathrm{ml}$ of monoclonal antibodies to mitochondrial protein (MCA1273) or COX (Molecular Probes). Immunoreactivity was revealed using the avidin-biotin horseradish peroxidase method (Vector Laboratories) and diaminobenzidine as the chromogen (Kirkegaard-Perry Laboratories, Gaithersburg, Maryland). The sections were then 
lightly counterstained with hematoxylin and preserved under coverglass. All sections were stained simultaneously using the same reagents, antibody dilutions, and incubation periods. As a positive control, adjacent sections were immunostained using monoclonal antibodies to glial fibrillary acidic protein, which was immunoreactive with all samples. As a negative control, adjacent sections were incubated with nonrelevant antibody to Hepatitis B virus surface antigen, which produced no immunostaining reaction in any of the specimens.

Image analysis was used to determine the degree to which cellular COX expression was reduced in AD and whether reductions in COX expression were more pronounced in the deeper (Layers 5 and 6) as compared with the more superficial (Layers 1-4) cortical regions. Threshold criteria for positive labeling were set to detect cells larger than $6 \mu \mathrm{M}$ with blue (hematoxylin-stained) nuclei and brown diaminobenzidine perikaryal precipitates. Cellular labeling was categorized as robust $(++)$, low-level $(+)$, or absent $(-)$. To reduce bias and permit analysis of the cases under code, the threshold criteria were set using sections of temporal cortex from additional control cases that were simultaneously immunostained but not included in the study. The laminar boundaries corresponding to Layers $1-4$ and 5 and 6 were defined in digitally captured images. Cells with,+++ , or -COX expression were enumerated within 20-200X adjacent microscopic fields (encompassing the fullthickness of cortical Layers 1-4 and Layers 5 and 6) using Image-Pro Plus software (Media Cybernetics, Silver Spring, Maryland). The overall percentages of cells that exhibited robust $(++)$, low-level $(+)$, or negative (-) COX expression were computed for each case, and those results were used to generate mean \pm SDS for each group. Intergroup comparisons were made using ANOVA and the Fisher Least Significant Difference post hoc test (NCSS Statistical Software, Kaysville, Utah). Random repeat analysis of samples yielded a coefficient of variation that was less than $10 \%$.

\section{References}

Ausubel FM, Brent R, Kingston RE, Moore DD, Seidman JG, Smith JA, and Struhl K (1998). Current protocols in molecular biology, ch 10. New York: John Wiley \& Sons.

Chandrasekaran K, Hatanpaa K, Brady DR, Stoll J, and Rapoport SI (1998). Downregulation of oxidative phosphorylation in Alzheimer disease: Loss of cytochrome oxidase subunit mRNA in the hippocampus and entorhinal cortex. Brain Res 796:13-19.

Davis J, Cribbs DH, Cotman CW, and Van Nostrand WE (1999). Pathogenic amyloid beta-protein induces apoptosis in cultured human cerebrovascular smooth muscle cells. Amyloid 6:157-164.

de la Monte S (1989). Quantitation of cerebral atrophy in preclinical and end-stage Alzheimer's disease. Ann Neurol 25:450-459. de la Monte S and Bloch K (1997). Aberrant expression of the constitutive endothelial nitric oxide synthase gene in Alzheimer's disease. Mol Chem Neuropathol 30:139-159.

de la Monte SM, Sohn YK, Ganju N, and Wands JR (1998). P53- and CD95-associated apoptosis in neurodegenerative diseases. Lab Invest 78:401-411.

de la Monte SM, Sohn YK, and Wands JR (1997). Correlates of p53- and Fas (CD95)-mediated apoptosis in Alzheimer's disease. J Neurol Sci 152:73-83.

Desjardins P and Ledoux S (1998). Expression of ced-3 and ced-9 homologs in Alzheimer's disease cerebral cortex. Neurosci Lett 244:69-72.

Durante W, Christodoulides N, Cheng K, Peyton KJ, Sunahara RK, and Schafer Al (1997). cAMP induces heme oxygenase-1 gene expression and carbon monoxide production in vascular smooth muscle. Am J Physiol 273:H317H323.

Erro E and Tunon T (1997). [Preliminary results of the study of neuronal death and the expression of bcl-2 protein in Alzheimer's disease]. Rev Med Univ Navarra 41:28-33.

Esiri M and Morris JE, editors (1997). The neuropathology of dementia. New York: Cambridge University Press, 70-101.

Forloni G, Bugiani O, Tagliavini F, and Salmona M (1996). Apoptosis-mediated neurotoxicity induced by beta-amyloid and PrP fragments. Mol Chem Neuropathol 28:163-171.

Giambarella U, Yamatsuji T, Okamoto T, Matsui T, Ikezu T, Murayama Y, Levine MA, Katz A, Gautam N, and Nishimoto I (1997). G protein betagamma complex-mediated apoptosis by familial Alzheimer's disease mutant of APP. EMBO J 16:4897-4907.

Gunn-Moore FJ and Tavare JM (1998). Apoptosis of cerebellar granule cells induced by serum withdrawal, glutamate or beta-amyloid, is independent of Jun kinase or p38 mitogen activated protein kinase activation. Neurosci Lett 250:53-56.

Hauswirth WW, Dickel CD, Rowold DJ, and Hauswirth MA (1994). Inter- and intrapopulation studies of ancient humans. Experientia 50:585-591.

Higuchi Y and Linn S (1995). Purification of all forms of HeLa cell mitochondrial DNA and assessment of damage to it caused by hydrogen peroxide treatment of mitochondria or cells. J Biol Chem 270:7950-7956.

Ivins KJ, Thornton PL, Rohn TT, and Cotman CW (1999). Neuronal apoptosis induced by beta-amyloid is mediated by caspase-8. Neurobiol Dis 6:440-449.

Kitamura $Y$, Shimohama S, Kamoshima W, Ota T, Matsuoka Y, Nomura Y, Smith MA, Perry G, Whitehouse PJ, and Taniguchi T (1998). Alteration of proteins regulating apoptosis, Bcl-2, Bcl-x, Bax, Bak, Bad, $\mathrm{ICH}-1$, and $\mathrm{CPP} 32$, in Alzheimer's disease. Brain Res 780:260-269.

Kurata S, Matsumoto, M., and Yamashita, U (1996). Concomitant transcriptional activation of nitric oxide synthase and heme oxygenase genes during nitric oxide-mediated macrophage cytostasis. J Biochem (Tokyo) 120:49-52.

Leist M, Fava E, Montecucco C, and Nicotera P (1997). Peroxynitrite and nitric oxide donors induce neuronal apoptosis by eliciting autocrine excitotoxicity. Eur $\mathrm{J}$ Neurosci 9:1488-1498.

Maines MD (1988). Heme oxygenase: Function, multiplicity, regulatory mechanisms, and clinical applications. FASEB $\mathrm{J}$ 2:2557-2568. 
Moyse E and Michel D (1997). Analyses of apoptosisassociated DNA fragmentation in vivo during neurodegeneration of the peripheral olfactory system in adult mammals. In: Poirier J, editor. Apoptosis techniques and protocols. Totowa, New Jersey: Humana Press, 133-159.

Nagy Z, Esiri MM, LeGris M, and Matthews PM (1999). Mitochondrial enzyme expression in the hippocampus in relation to Alzheimer-type pathology. Acta Neuropathol (Berl) 97:346-354.

Ozawa T (1997). Genetic and functional changes in mitochondria associated with aging. Physiol Rev 77:425-464.

Ozawa T (1995). Mitochondrial DNA mutations associated with aging and degenerative diseases. Exp Gerontol 30:269 290.

Pappolla MA, Chyan YJ, Omar RA, Hsiao K, Perry G, Smith $M A$, and Bozner $P$ (1998). Evidence of oxidative stress and in vivo neurotoxicity of beta-amyloid in a transgenic mouse model of Alzheimer's disease: A chronic oxidative paradigm for testing antioxidant therapies in vivo. Am J Pathol 152: 871-877.

Paradis E, Douillard H, Koutroumanis M, Goodyer C, and LeBlanc A (1996). Amyloid beta peptide of Alzheimer's disease downregulates $\mathrm{Bcl}-2$ and upregulates bax expression in human neurons. J Neurosci 16:7533-7539.

Pou S, Pou W, Bredt D, Snyder S, and Rosen G (1992). Generation of superoxide by purified brain nitric oxide synthase. J Biol Chem 267:24173-24176.

Prehn JH, Bindokas VP, Jordan J, Galindo MF, Ghadge GD, Roos RP, Boise LH, Thompson CB, Krajewski S, Reed JC, and Miller RJ (1996). Protective effect of transforming growth factor-beta 1 on beta-amyloid neurotoxicity in rat hippocampal neurons. Mol Pharmacol 49:319-328.

Premkumar DR, Smith MA, Richey PL, Petersen RB, Castellani R, Kutty RK, Wiggert B, Perry G, and Kalaria RN (1995). Induction of heme oxygenase-1 mRNA and protein in neocortex and cerebral vessels in Alzheimer's disease. J Neurochem 65:1399-1402.

Richter C (1992). Reactive oxygen and DNA damage in mitochondria. Mutat Res 275:249-55.

Richter C (1995). Oxidative damage to mitochondrial DNA and its relationship to aging. Int J Biochem Cell Biol 27:647653.

Sayre LM, Zagorski MG, Surewicz WK, Krafft GA, and Perry G (1997a). Mechanisms of neurotoxicity associated with amyloid beta deposition and the role of free radicals in the pathogenesis of Alzheimer's disease: A critical appraisal. Chem Res Toxicol 10:518-526.

Sayre LM, Zelasko DA, Harris PL, Perry G, Salomon RG, and Smith MA (1997b). 4-Hydroxynonenal-derived advanced lipid peroxidation end products are increased in Alzheimer's disease. J Neurochem 68:2092-2097.

Schapira AHV (1994). Mitochondrial dysfunction in neurodegenerative disorders and aging. In: Schapira AHV and DiMauro S, editors. Mitochondrial disorders in neurology. Oxford: Butterworth-Heinemann, 227-244.

Schipper HM, Cisse S, and Stopa EG (1995). Expression of heme oxygenase- 1 in the senescent and Alzheimer-diseased brain. Ann Neurol 37:758-768.
Schmidt H and Walter U (1994). NO at work. Cell 78:919925.

Seki T, Naruse M, Naruse K, Yoshimoto T, Tanabe A, Imaki T, Hagiwara H, Hirose S, and Demura H (1997). Interrelation between nitric oxide synthase and heme oxygenase in rat endothelial cells. Eur J Pharmacol 331:87-91.

Smith MA, Harris PL, Sayre LM, and Perry G (1997). Iron accumulation in Alzheimer disease is a source of redoxgenerated free radicals. Proc Natl Acad Sci U S A 94:98669868.

Smith MA and Perry G (1995). Free radical damage, iron, and Alzheimer's disease. J Neurol Sci 134(Suppl): 92-94.

Smith MA, Sayre LM, Monnier VM, and Perry G (1996). Oxidative posttranslational modifications in Alzheimer disease. A possible pathogenic role in the formation of senile plaques and neurofibrillary tangles. Mol Chem Neuropathol 28:41-48.

Sohn YK, Ganju N, Bloch KD, Wands JR, and de la Monte SM (1999). Neuritic sprouting with aberrant expression of the nitric oxide synthase III gene in neurodegenerative diseases. J Neurol Sci 162:133-151.

Stadelmann C, Bruck W, Bancher C, Jellinger K, and Lassmann H (1998). Alzheimer disease: DNA fragmentation indicates increased neuronal vulnerability, but not apoptosis. J Neuropathol Exp Neurol 57:456-464.

Stamler J (1994). Redox signaling: Nitration and related target interactions of nitric oxide (Review). Cell 78:931-936.

Su JH, Deng G, and Cotman CW (1997). Bax protein expression is increased in Alzheimer's brain: Correlations with DNA damage, Bcl-2 expression, and brain pathology. J Neuropathol Exp Neurol 56:86-93.

Su JH, Satou T, Anderson AJ, and Cotman CW (1996). Up-regulation of $\mathrm{Bcl}-2$ is associated with neuronal DNA damage in Alzheimer's disease. Neuroreport 7:437-440.

Tortosa, A., Lopez, E., and Ferrer, I (1998). Bcl-2 and Bax protein expression in Alzheimer's disease. Acta Neuropathol (Berl) 95:407-12.

Wong-Riley M, Antuono P, Ho KC, Egan R, Hevner R, Liebl W, Huang Z, Rachel R, and Jones J (1997). Cytochrome oxidase in Alzheimer's disease: Biochemical, histochemical, and immunohistochemical analyses of the visual and other systems. Vision Res 37:3593-3608.

Xia Y, Dawson V, Dawson T, Snyder S, and Zweier J (1996). Nitric oxide synthase generates superoxide and nitric oxide in arginine-depleted cells leading to peroxynitrite-mediated cellular injury. Proc Natl Acad Sci U S A 93:6770-6774.

Yamatsuji T, Okamoto T, Takeda S, Murayama Y, Tanaka N, and Nishimoto I (1996). Expression of V642 APP mutant causes cellular apoptosis as Alzheimer trait-linked phenotype. EMBO J 15:498-509.

Yan SD, Yan SF, Chen X, Fu J, Chen M, Kuppusamy P, Smith MA, Perry G, Godman GC, and Nawroth P (1995). Nonenzymatically glycated tau in Alzheimer's disease induces neuronal oxidant stress resulting in cytokine gene expression and release of amyloid beta-peptide. Nat Med 1:693-699. 